\title{
Rapid discrimination of the common species of the stored product pest Liposcelis (Psocoptera: Liposcelididae) from China and the Czech Republic, based on PCR-RFLP analysis
}

\author{
Meng QIN ${ }^{1}$, Zhi-Hong LI ${ }^{1 *}, Z_{\text {ZUANA KUČEROVÁ }}^{2 *}$, YANG CAO $^{3}$ and VÁclav STEJSKAL ${ }^{2}$ \\ ${ }^{1}$ Department of Plant Protection and Quarantine, College of Agronomy and Biotechnology, China Agricultural University, \\ 2 Yuanmingyuan, West Road, Beijing 100094, China \\ ${ }^{2}$ Crop Research Institute, Drnovská 507, 16106 Prague 6, Czech Republic \\ ${ }^{3}$ The Academy of Science of the State Administration of Grain, Beijing 100037, China
}

Key words. Psocoptera, storage pests, Liposcelis, booklice, PCR-RFLP, 16S rDNA, sequencing

\begin{abstract}
Psocids of the genus Liposcelis (Psocoptera: Liposcelididae) are stored product pests that are difficult to identify morphologically. A molecular method based on Restriction Fragment Length Polymorphism (RFLP) of the PCR-amplified 16S rDNA gene was developed for the rapid discrimination of four common species (L. bostrychophila, L. entomophila, L. decolor, and L. paeta). Different developmental stages and populations (P.R. China and Czech Republic) were tested. One DNA fragment of about 500 bp in length was amplified from genomic DNA and the fragment was then digested using the restriction endonuclease DraI. Identification of the relevant banding pattern allowed all the developmental stages and both sexes to be discriminated in the species tested. The banding patterns of $L$. entomophila from all populations were identical, while the relevant restriction digests and sequence analysis confirmed that the Chinese and Czech populations of L. bostrychophila, L. decolor, and L. paeta differed. In conclusion, PCR-RFLP with one pair of primers (16Sar and 16Sbr) and one restrictive endonuclease, DraI, proved a reliable method for rapidly discriminating the Liposcelis species tested.
\end{abstract}

\section{INTRODUCTION}

In the last decade, psocids (booklice) have become economically important pests of stored commodities (Ding et al., 2002; Beckett \& Morton, 2003; Kučerová et al., 2003; Nayak et al., 2003; Stejskal et al., 2003; Nayak, 2006). Species of Liposcelis have frequently been captured during quarantine inspections at ports in China. The genus Liposcelis Motschulsky (Psocoptera: Liposcelididae) contains 123 species (Li, 2002; Lienhard \& Smithers, 2002; Wang et al., 2006), of which several are of economic importance. Liposcelis bostrychophila Badonnel, L. entomophila (Enderlein), L. decolor (Pearman) and L. paeta Pearman are the most commonly occurring species of Liposcelis in stored products such as grain, animal specimens and archives (Turner, 1994; Baz \& Monserrat, 1999; Li et al., 1999; Li, 2001; Rees, 2004).

Correct identification of psocid species is a prerequisite for the establishment of an effective pest management program. Traditional morphological identification of Liposcelis adults (Lienhard, 1990; Bai \& Cao, 1997; Li et al., 1999; Lienhard \& Smithers, 2002) or of the immature stages (Kučerová, 2002) is difficult and requires specialists. Methods for rapidly identifying booklice are unavailable. Molecular techniques based on DNA analysis offer a viable and economical alternative method of identification (Muraji \& Nakahara, 2001). Different DNA and Polymerase Chain Reaction (PCR)-based molecular markers have been developed for insect diagnostic pur- poses, including Random Amplified Polymorphic DNA (RAPD), Restriction Fragment Length Polymorphisms (RFLP), satellite DNA, and Inter-Simple Sequence Repeats (ISSR) (Li, 2007). The nucleotide sequences of Liposcelis have been analyzed in order to infer phylogenetic relationships, geographic origin, population genetics or gene flow (Cruickshank et al., 2001; Barker et al., 2003; Johnson \& Mockford, 2003; Yoshizawa \& Johnson, 2003; Mikac, 2006, 2007; Mikac \& Clarke, 2006). As a result, more than 60 sequences have been submitted to international DNA sequence databases, such as the DNA Data Bank of Japan (DDBJ), European Molecular Biology Laboratory (EMBL), and GenBank. Using these Liposcelis DNA sequences, we have analyzed a rapid discrimination method for Liposcelis from China based primarily on PCR-RFLP (Qin et al., 2007).

In this study, the above discrimination investigations are extended by extracting genetic DNA from single individuals and using PCR-RFLP to discriminate between four species of Liposcelis originating from the People's Republic of China (P.R. China) and Czech Republic (CZ), L. bostrychophila, L. entomophila, L. decolor, and L. paeta.

\section{MATERIAL AND METHODS}

\section{Insect collection and culture}

Liposcelis bostrychophila, L. entomophila, L. decolor, and $L$. paeta were collected in storehouses in the P.R. China and CZ

\footnotetext{
* Corresponding authors; e-mails: lizh@cau.edu.cn; kucerova@vurv.cz
} 
(12 geographical populations - Table 1). Adult identification was confirmed by C. Lienhard (Museum of Natural History, Geneva, Switzerland). The rearing diet consisted of wholewheat flour: skimmed milk powder: yeast powder in a ratio of $10: 1: 1$ (Ding et al., 2001). The insects were kept at $27-28.5^{\circ} \mathrm{C}$ and $75-80 \% \mathrm{RH}$. Males, females, and nymphs of each species and geographical population (20 individuals of each species and developmental stage) were subjected to PCRRFLP. In the parthenogenetic L. bostrychophila, females and nymphs were tested. The PCR products from a single individual of each of the species L. bostrychophila, L. decolor, and $L$. paeta was additionally analyzed by sequencing. All psocids were killed in $100 \%$ ethanol and their DNA extracted immediately.

\section{DNA extraction}

Genomic DNA was extracted from each geographical population of each species using the method of Gong et al. (2002), which is a slight modification based on the method of cetyltrimethylammonium bromide (CTAB).

\section{PCR amplification}

16S rDNA was amplified using the primers 16Sar and 16Sbr (Simon et al., 1994): the 16Sar primer has the sequence 5'GCCTGTTTAACAAAAACAT-3', and the 16Sbr primer has the sequence 5'-CCGGTCTGAACTCAGATCACGT-3'. PCR was then carried out in a $20 \mu \mathrm{l}$ reaction volume containing 2.0 $\mu 1$ of $10 \times$ reaction buffer, $2.0 \mu \mathrm{l}(25 \mathrm{mM}) \mathrm{MgCl}_{2}, 0.5 \mu \mathrm{l}(2.5$ $\mathrm{mM}) \mathrm{dNTPs}, 1 \mu \mathrm{l}(5 \mu \mathrm{M})$ of each primer (two primers), $1 \mu \mathrm{l}$ $(1 \mathrm{U} / \mu \mathrm{l}) \mathrm{Taq}$ DNA polymerase (TianGen, Beijing, China), $1 \mu \mathrm{l}$ (50-100 ng) template DNA, and $11.5 \mu \mathrm{l}$ double distilled water $\left(\mathrm{ddH}_{2} \mathrm{O}\right)$. The thermal cycling conditions were: initial denaturation at $95^{\circ} \mathrm{C}$ for $3 \mathrm{~min}$, followed by 35 cycles of denaturation at $95^{\circ} \mathrm{C}$ for $45 \mathrm{~s}$, annealing at $50^{\circ} \mathrm{C}$ for $45 \mathrm{~s}$, extension at $72^{\circ} \mathrm{C}$ for $45 \mathrm{~s}$ and a final extension step at $72^{\circ} \mathrm{C}$ for $10 \mathrm{~min}$. After amplification, $5 \mu \mathrm{L}$ of the PCR products were subjected to electrophoresis alongside a DNA marker.

\section{Restriction endonuclease digestion and sequencing}

Restriction endonuclease digestion was performed in a $20 \mu \mathrm{l}$ reaction volume containing $10 \mu \mathrm{l}$ of the target DNA (PCR product), $2 \mu \mathrm{l}$ restriction buffer, $1 \mu \mathrm{l}$ restriction endonuclease (DraI)

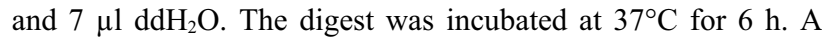
$3.5 \%-4.0 \%(\mathrm{w} / \mathrm{v})$ agarose gel was made from $1 \times \mathrm{TBE}$ buffer, and $8 \mu 1$ of the digested PCR product was subjected to electrophoresis alongside a DNA marker.

This sequencing method was used on the following species. Genomic DNA of Liposcelis bostrychophila, L. decolor, and L. paeta was extracted from a single individual of each species and the 16S rDNA gene amplified using the 16Sar and 16Sbr primers. The amplified products were then separated on a $1.0 \%(\mathrm{w} / \mathrm{v})$ agarose gel $(1 \times \mathrm{TAE})$, and the bands (stained with ethidium bromide) were excised. The agarose gel slice containing the DNA band of interest was placed in a centrifuge tube. The DNA was then purified and cloned, then the bacterial liquid culture was used as a template for nucleotide sequencing (AuGCT Biotechnology Synthesis Lab, Beijing, China). DNAMAN software was used for restriction analysis of the six sequences.

\section{RESULTS}

\section{PCR analysis}

All of the PCR products were nearly the same size ( $\sim 500 \mathrm{bp})$. The PCR products were not influenced by species, geographical population, stage of development or sex.
TABLE 1. Liposcelis species and populations used in this study (populations were coded by combining species names with acronyms of collection countries and sites).

\begin{tabular}{ll}
\hline Population & Location collected \\
\hline L. entomophila_HB-P.R.China & Hubei, P.R. China \\
L. entomophila_CQ-P.R.China & Chongqing, P.R. China \\
L. entomophila_P-CZ & Central Bohemia, Czech Rep. \\
L. bostrychophila_GX-P.R.China & Guangxi, P.R. China \\
L. bostrychophila_CQ-P.R.China & Chongqing, P.R. China \\
L. bostrychophila_P-CZ & Central Bohemia, Czech Rep. \\
L. decolor_CQ-P.R.China & Chongqing, P.R. China \\
L. decolor_HN-P.R.China & Henan, P.R. China \\
L. decolor_P-CZ & Central Bohemia, Czech Rep. \\
L.paeta_ZJ-P.R.China & Zhejiang, P.R. China \\
L.paeta_JX-P.R.China & Jiangxi, P.R. China \\
L.paeta_P-CZ & Central Bohemia, Czech Rep. \\
\hline
\end{tabular}

\section{RFLP and sequencing analysis}

The PCR products could be digested at specific regions. Though different Liposcelis species could be visually distinguished according to their electrophoresis patterns, digestion result of Liposcelis of the same species was not influenced by individuality, sex or developmental stage.

Samples from the P.R. China

16S rDNA of four species of Liposcelis were successfully cut into distinct visible bands. Four bands ( $\sim 300 \mathrm{bp}$, $120 \mathrm{bp}, 70 \mathrm{bp}$, and $50 \mathrm{bp}$ ) were visible in the 16S rDNA of L. entomophila; two clear bands of different sizes ( $\sim 350 \mathrm{bp}$ and $100 \mathrm{bp} ; \sim 350 \mathrm{bp}$, and $200 \mathrm{bp} ; \sim 300 \mathrm{bp}$ and $220 \mathrm{bp}$ ) were seen in the $16 \mathrm{~S}$ rDNA of L. bostrychophila, L. decolor, and L. paeta, respectively. These results demonstrate that restriction endonuclease digestion was not affected by the different geographical populations, stages of development or sex of the four common species of the stored product pest Liposcelis from the P.R. China (Fig. 1).

Samples from the CZ and comparison with those from the P.R. China

The repeated experiments on the $\mathrm{CZ}$ samples produced identical results, and were not influenced by stage of development or sex. 16S rDNA of L. entomophila was excised into four visible bands ( 300 bp, $120 \mathrm{bp}, 70 \mathrm{bp}$ and $50 \mathrm{bp})$, which were identical with those result obtained for the P.R. China samples. For the other three Liposcelis species, i.e. L. bostrychophila, L. decolor, and L. paeta, the sizes of these fragments differed from those the samples from the P.R. China (Fig. 2). Therefore, the different visible bands observed after restriction digestion of $16 \mathrm{~S}$ rDNA were further analyzed and confirmed by sequencing. The results showed that the sequences from the same species exhibited a high level similarity, with limited genetic mutations. Fig. 3 shows the sequence lengths and digestion sites. For L. bostrychophila, the 16S rDNA of the sample from the P.R. China had 3 digestion sites and 4 fragments of $326 \mathrm{bp}, 100 \mathrm{bp}, 34 \mathrm{bp}$, and $33 \mathrm{bp}$, 


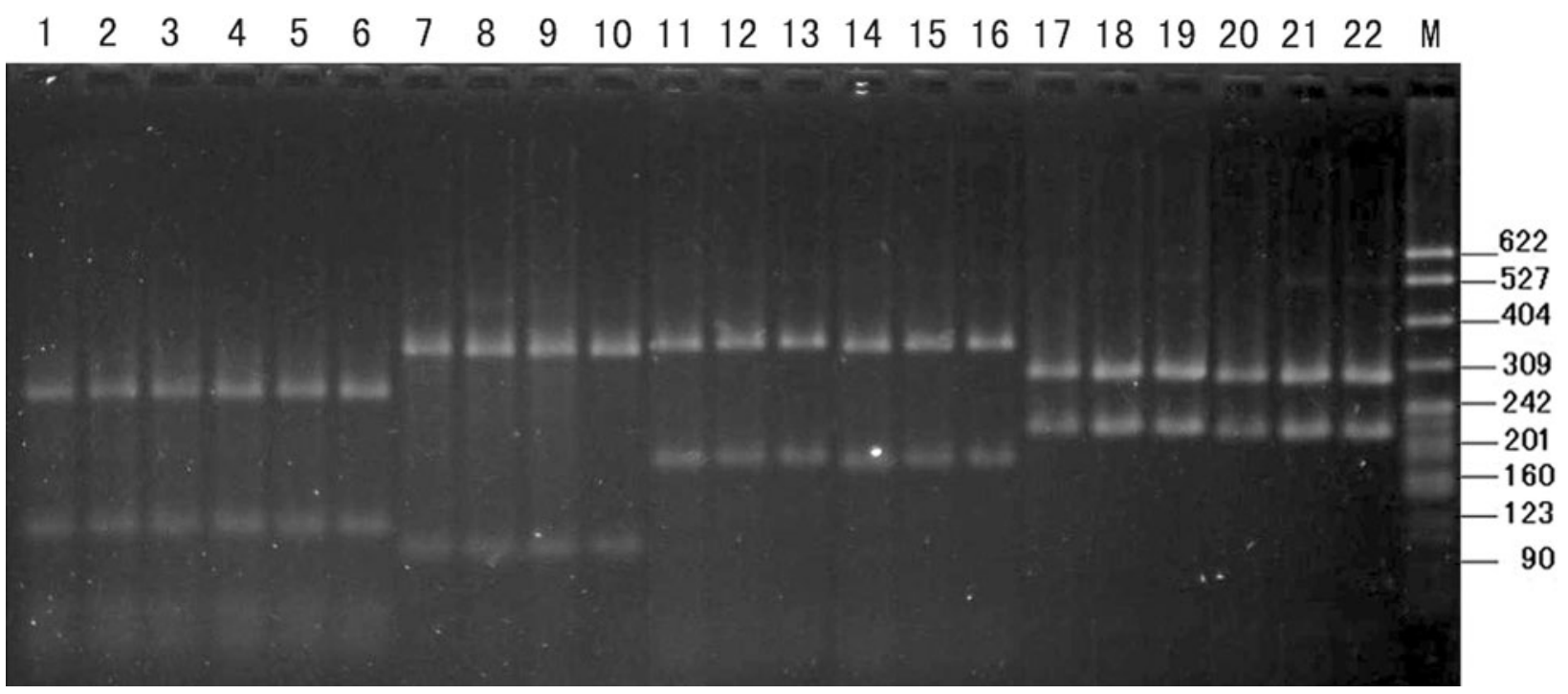

Fig. 1. Electrophoresis of DraI-digested PCR products from the 16S rDNA of four common species of stored Liposcelis from the P.R. China. Lanes: 1-3 - female, male, and nymphs of $L$. entomophila_HB-P.R.China; 4-6 - female, male, and nymphs of $L$. entomophila_CQ-P.R.China; 7-8 - female and nymphs of L. bostrychophila_GX-P.R.China; 9-10 - female and nymphs of $L$. bostrychophila_CQ-P.R.China; 11-13 - female, male, and nymphs of L. decolor_CQ-P.R.China; 14-16 - female, male, and nymphs of L. decolor_HN-P.R.China; 17-19 - female, male, and nymphs of L. paeta_ZJ-P.R.China; 20-22 - female, male, and nymphs of L. paeta_JX-P.P.R.China; M - molecular size marker (bp).

and the $16 \mathrm{~S}$ rDNA of the sample from $\mathrm{CZ}$ had 2 digestion sites and 3 fragments of $225 \mathrm{bp}, 192 \mathrm{bp}$, and $72 \mathrm{bp}$. The 16S rDNA of L. decolor from the P.R. China and CZ displayed 1 digestion site and 2 fragments (338 bp and 167 bp; $337 \mathrm{bp}$ and $168 \mathrm{bp}$, respectively). For L. paeta, the $16 \mathrm{~S}$ rDNA of the sample from the P.R. China had only 1 digestion site, and 2 fragments of $279 \mathrm{bp}$, and $201 \mathrm{bp}$, but that of the sample from the $\mathrm{CZ}$ had 3 digestion sites and 4

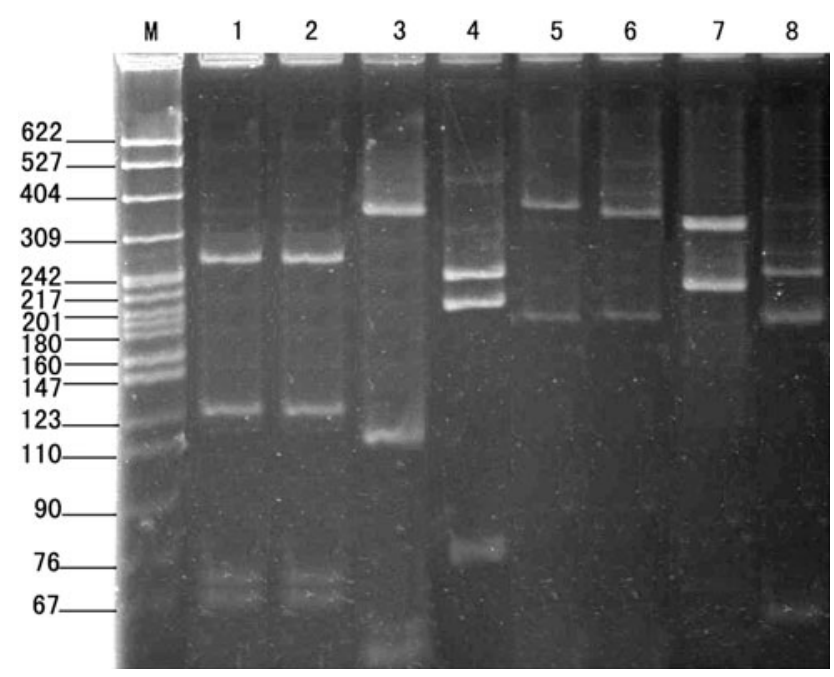

Fig. 2. Electrophoresis of DraI-digested PCR products of $16 \mathrm{~S}$ rDNA from four common species of Liposcelis from the P.R. China and CZ. Lanes: M - molecular size marker (bp); 1 female of $L$. entomophila_HB-P.R.China; 2 - female of $L$. entomophila_P-CZ; 3 - female of L. bostrychophila_GX-P.R. China; 4 - female of $L$. bostrychophila_P-CZ; 5 - female of $L$. decolor CQ-P.R.China; 6 - female of $L$. decolor P-CZ; 7 female of L.paeta_ZJ-P.R. China; 8 - female of L. paeta_P-CZ. fragments of $200 \mathrm{bp}, 184 \mathrm{bp}, 62 \mathrm{bp}$ and $33 \mathrm{bp}$. The sequencing results showed that the mutation points in $16 \mathrm{~S}$ rDNA were consistent with the banding patterns of the electrophoresis map, except for some small fragments that could not be detected by agarose gel electrophoresis.

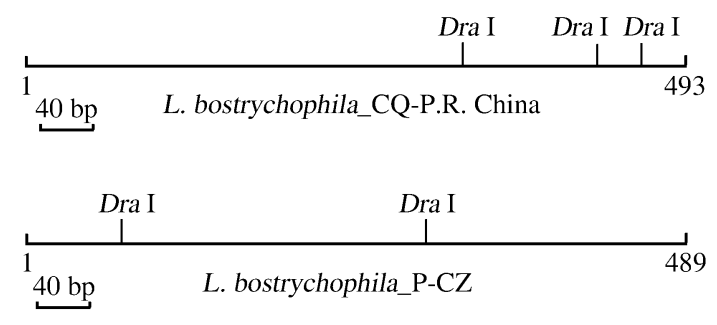

\begin{tabular}{l}
\multicolumn{2}{c}{ Dra I } \\
$150 \mathrm{bp}$ \\
\hline
\end{tabular}
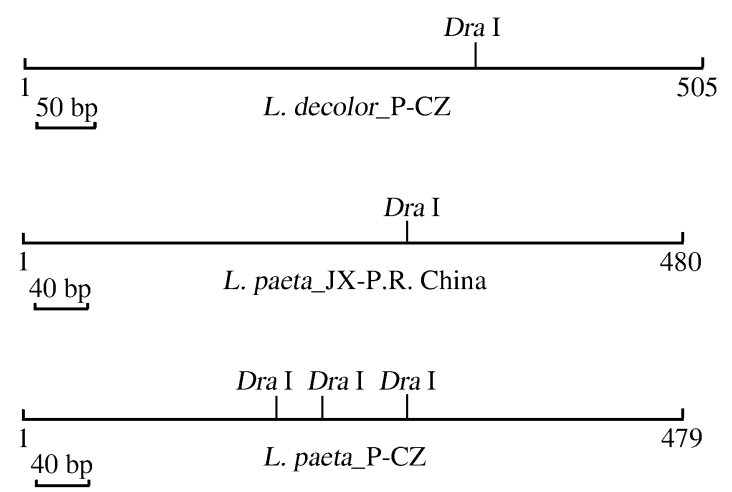

Fig. 3. Restrictive endonuclease sites of six samples produced by sequencing. 


\section{DISCUSSION}

In this report, we show that PCR-RFLP based on $16 \mathrm{~S}$ rDNA is an efficient way of rapidly discriminating four storage pest psocids from the P.R. China and CZ. One pair of primers $16 \mathrm{Sar} / \mathrm{Sbr}$ and one restrictive endonuclease, DraI, are sufficient to discriminate between the Liposcelis species tested. The whole process from extraction of genomic DNA to the formation of a restriction map takes only $12 \mathrm{~h}$. This rapid molecular method can be used by plant quarantine offices to identify the most commonly occurring species of Liposcelis infesting stored products.

The results of this study indicate that the PCR-RFLP method is able to identify L. entomophila using the same digestion pattern of $16 \mathrm{~S}$ rDNA, regardless of differences between geographical populations, stages of development or sex of the individuals in the samples. In comparison, $L$. bostrychophila, L. decolor, and L. paeta were well discriminated, but the numbers or sizes of the $16 \mathrm{~S}$ rDNA band differed, even for the same species. For each species of these three psocids, the $16 \mathrm{~S}$ rDNA of the P.R. China and $\mathrm{CZ}$ populations showed different stable electrophoresis patterns. Further, the sequence analysis indicated that the points of mutation in the 16S rDNA are consistent with the electrophoresis patterns. This enabled us to conclude that there are intraspecific genetic differences between the P.R. China and CZ populations of $L$. bostrychophila, L. decolor, and L. paeta. Further worldwide geographical studies are required in order to draw general conclusions regarding intra-specific genetic differences in Liposcelis.

Recently, molecular methods have been used to detect natural populations of Diptera, Coleoptera, Hymenoptera, and Lepidoptera (Ratcliffe et al., 2002; Loxdale \& MacDonald, 2004; Gómez-Zurita et al., 2005; Li, 2007). The common methods used are RAPD analysis, RFLP patterns, Amplified Fragment Length Polymorphism (AFLP) molecular markers, species-specific primers, and ISSR. Of these methods, PCR-RFLP analysis of molecular markers is regarded as an easy, fast and reliable method (Muraji \& Nakahara, 2002) for identifying closely related species that have an ambiguous taxonomic status, similar insect species that are difficult to identify using morphological characteristics and the immature stages of insects (Sperling et al., 1994; Tuda et al., 1995; Litjens et al., 2001; Zapata et al., 2007). Since different genetic mutations occur in DNA sequences in species during evolution, it is possible to find different points of discrimination using restriction endonucleases. Based on this study, it may be concluded that the PCR-RFLP method with one pair of primers, $16 \mathrm{Sar} / \mathrm{Sbr}$, and one restrictive endonuclease, DraI, is a convenient and reliable way to rapidly discriminate between the four common species of stored product psocids. This method can detect the species of Liposcelis studied not only the adults, but also the immature stages. Moreover it confirmed that this method is able to reveal some intra-specific differences associated with the geographical distribution of these species. Further molecular research on other psocid species and their geographical strains on a worldwide scale is needed in the future.

ACKNOWLEDGEMENTS. The authors would like to thank C. Lienhard (Museum of Natural History, Geneva, Switzerland) for reading the MS and confirming the species identification. We would also like to acknowledge F. Li (State Administration of Grain, P.R. China), S. Lan and H. Zhou (Chengdu Grain Storage Research Institute, P.R. China) for their advice. This study was supported by No. 37-22, No. 38-46 of Chinese-Czech cooperation projects (PRC) and the program of international cooperation No. 1P05ME733-KONTAKT (CZ).

\section{REFERENCES}

BAI X.G. \& CAO Y. 1997: Two new findings of the genus Liposcelis from the stored grain in China. J. Chin. Cereals Oils Assoc. 12: 1-4 [in Chinese].

Barker S.C., Whiting M., Johnson K.P. \& Murrell A. 2003: Phylogeny of the lice (Insect: Phthiraptera) inferred from small subunit rRNA. Zool. Scr. 32: 407-414.

Baz A. \& Monserrat V.J. 1999: Distribution of domestic Psocoptera in Madrid apartments. Med. Vet. Entomol. 13: 259-264.

BeCKetT S.J. \& MoRton R. 2003: The mortality of three species of Psocoptera, Liposcelis bostrychophila Badonnel, Liposcelis decolor Pearman and Liposcelis paeta Pearman, at moderately elevated temperatures. J. Stored Prod. Res. 39: 103-115.

Cruickshank R.H., Johnson K.P., Smith V.S., Adams R.J., Clayton D.H. \& Page R.D. 2001: Phylogenetic analysis of partial sequences of elongation factor lalpha identifies major groups of lice (Insecta: Phthiraptera). Mol. Phylogenet. Evol. 19: $202-215$.

Ding W., Wang J.J. \& Zhao Z.M. 2001: Study on the breeding conditions for the laboratory populations of booklouse (Liposcelis). J. Southw. Agri. Univ. 23: 304-306 [in Chinese].

Ding W., Wang J.J., Zhao Z.M. \& James H.T. 2002: Effects of controlled atmosphere and DDVP on population growth and resistance development by the psocid, Liposcelis bostrychophila Badonnel (Psocoptera: Liposcelididae). J. Stored Prod. Res. 38: 229-237.

Gómez-Zurita J., Jolivet P. \& Vogler A.P. 2005: Molecular systematics of Eumolpinae and the relationships with Spilopyrinae (Coleoptera, Chrysomelidae). Mol. Phylogenet. Evol. 34: 584-600.

Gong P., Shen Z.R. \& Li Z.H. 2002: PCR-based detection of Wolbachia infected in natural populations of wheat aphids in China. Entomol. Knowl. 39: 188-190 [in Chinese].

Johnson K.P. \& Mockford E.L. 2003: Molecular systematics of Psocomorpha (Psocoptera). Syst. Entomol. 28: 409-416.

KuČEROVÁ Z. 2002: Stored product psocids (Psocoptera): External morphology of eggs. Eur. J. Entomol. 99: 491-503.

Kučerová Z., AulickÝ R. \& Stejskal V. 2003: Accumulation of pest-arthropods in grain residues found in an empty store. $J$. Plant Dis. Protect. 110: 499-504.

Li F.S. 2002: Psocoptera of China. Science Press, Beijing, pp. 77-102 [in Chinese].

Li Z.H. 2001: Species and identification of store booklice in China. Adv. Urb. Entomol. 6: 197-201 [in Chinese].

Li Z.X. 2007: Molecular differentiation of the four most commonly occurring Trichogramma (Hymenoptera: Trichogrammatidae) species in China. Eur. J. Entomol. 104: 363-367.

Li Z.H., Li F.S. \& Zhang B.F. 1999: A taxonomic study on the genus Liposcelis from China. Plant Quarant. 13: 266-271 [in Chinese]. 
Lienhard C. 1990: Revision of the western Palaearctic species of Liposcelis Motschulsky (Psocoptera: Liposcelididae). Zool. Jb. Syst. 117: 117-174.

Lienhard C. \& Smithers C.N. 2002: Psocoptera - World Catalogue and Bibliography. Instrumenta Biodiversitatis $\mathrm{V}$. Muséum d'Histoire Naturelle, Genève, 745 pp.

Litjens P., Lessinger A.C. \& Lima A.M. 2001: Characterization of the screwworm flies Cochliomyia hominivorax and Cochliomyia macellaria by PCR-RFLP of mitochondrial DNA. Med. Vet. Entomol. 15: 183-188.

Loxdale H. \& MacDonald C. 2004: Tracking parasitoids at the farmland field scale using microsatellites markers. In Werner D. (ed.): Biological Resources and Migration. Proceedings of the International Conference and OECD Workshop. Springer, Berlin, pp. 107-126.

MIKAC K.M. 2006: Isolation and characterisation of the first microsatellite loci from the Order Psocoptera in the economically important pest insect Liposcelis decolor (Pearman) and cross-species amplification. Mol. Ecol. Notes 6: 1102-1104.

MIKAC K.M. 2007: The population genetics of the invasive Psocoptera (Liposcelididae) species Liposcelis bostrychophila Badonnel and Liposcelis decolor (Pearman) in Australian grain storage systems. Aust. J. Entomol. 46: 258-259.

MikaC K.M. \& Clarke G.M. 2006: Tracing the geographic origin of the cosmopolitan parthenogenetic insect pest Liposcelis bostrychophila (Psocoptera: Liposcelididae). Bull. Entomol. Res. 96: 523-530.

Muraji M. \& NaKahara S. 2001: Phylogenetic relationships among fruit flies, Bactrocera (Diptera, Tephritidae), based on the mitochondrial rDNA sequences. Insect Mol. Biol. 10 $549-559$.

Muraji M. \& Nakahara S. 2002: Discrimination among pest species of Bactrocera (Diptera, Tephritidae) based on PCRRFLP of the mitochondrial DNA. Appl. Entomol. Zool. 37: $437-446$

NAYAK M.K. 2006: Psocid and mite pests of stored commodities: small but formidable enemies. In Lorini I. et al. (eds): Proceedings of the 9th International Working Conference on Stored Product Protection, 15-18 October 2006, Campinas, São Paulo, Brazil. Brazilian Post-harvest Association - ABRAPOS, Passo Fundo, RS, pp. 1061-1073.

Nayak M.K., Collins P.J. \& Kopittke R.A. 2003: Residual toxicities and persistence of organophosphorus insecticides mixed with carbaryl as structural treatments against three liposcelidid psocid species (Psocoptera: Liposcelididae) infesting stored grain. J. Stored Prod. Res. 39: 343-353.
Qin M., Li Z.H., Sun X., Kang F.F. \& Wu Y. 2007: Rapid discrimination of four common species of store booklice (Liposcelididae: Liposcelis) from China using PCR-RFLP. Chin. Bull. Entomol. 44: 909-912 [in Chinese].

Ratcliffe S.T., Robertson H.M., Jones C.J., Bollero E.A. \& WeinZIERL R.A. 2002: Assessment of house fly and stable fly pupae (Diptera: Muscidae) by Pteromalid (Hymenoptera: Pteromalidae) parasitoids using polymerase chain reaction. $J$. Med. Entomol. 39: 52-60.

ReES D.P. 2004: Insects of Stored Products. CSIRO, Collingwood, $181 \mathrm{pp}$.

Simon C., Frati F., Beckenbach A., Crespi B., Liu H. \& Flook P. 1994: Evolution, weighting and phylogenetic utility of mitochondrial gene sequences and a compilation of conserved polymerase chain reaction primers. Ann. Entomol. Soc. Am. 87: 651-701.

Sperling F.A.H., Anderson G.S. \& Hickey D.A. 1994: DNAbased approach to the identification of insect species used for postmortem interval estimation. J. Forensic Sci. 39: 418-427.

Stejskal V., Hubert J., KuČerová Z., Munzbergová Z., LuKáš J. \& Ž ̌̌ÁRKOVÁ E. 2003: The influence of type of storage on pest infestation of stored grain in the Czech Republic. Plant Soil Environ. 49: 55-62.

Tuda M., Fukatsu T. \& Shimada M. 1995: Species differentiation of bruchid beetles (Coleoptera: Bruchidae) analyzed by mitochondrial DNA polymorphism. Appl. Entomol. Zool. 30: 377-380.

TURNER B.D. 1994: Liposcelis bostrychophila (Psocoptera, Liposcelididae), a stored-food pest in the UK. Pest Manag. Sci. 40: 179-190.

Wang Z.Y., Wang J.J. \& Lienhard C. 2006: Two new species of Liposcelis (Psocoptera, Liposcelididae). Acta Zootax. Sin. 31: 564-568.

Yoshizawa K. \& Johnson K.P. 2003: Phylogenetic position of Phthiraptera (Insecta: Paraneoptera) and elevated rate of evolution in mitochondrial $12 \mathrm{~S}$ and $16 \mathrm{~S}$ rDNA. Mol. Phylogenet. Evol. 29: 102-114.

Zapata M.A., Cienfuegos A.V., Quiros O.I., Quinones M.L., LUCKHART S. \& CORREA M.M. 2007: Discrimination of seven Anopheles species from San Pedro de Uraba, Antioquia, Colombia, by polymerase chain reaction-restriction fragment length polymorphism analysis of its sequences. Am. J. Trop. Med. Hyg. 77: 67-72.

Received February 13, 2008; revised and accepted April 11, 2008 